\title{
Iodine Content of Salt Use after Years of Universal Iodization Policy and Knowledge on Iodized Salt among Households in the Sissala East Municipality in Upper West Region of Ghana
}

\author{
Prince Kubi Appiah (D), ${ }^{1}$ Clement Tiimim Yanbom, ${ }^{1}$ Martin Amogre Ayanore ${ }^{D},{ }^{2}$ \\ and Alex Bapula ${ }^{3}$ \\ ${ }^{1}$ Department of Family and Community Health, School of Public Health, University of Health and Allied Sciences, Ho, Ghana \\ ${ }^{2}$ Department of Health Policy Planning and Management, School of Public Health, University of Health and Allied Sciences, \\ Ho, Ghana \\ ${ }^{3}$ Municipal Health Directorate, Ghana Health Service, Sissala East Municipal, Upper West Region, Accra, Ghana
}

Correspondence should be addressed to Prince Kubi Appiah; appiahkubiprince23@yahoo.com

Received 18 November 2019; Revised 19 January 2020; Accepted 22 January 2020; Published 18 February 2020

Academic Editor: Barbara Speranza

Copyright (c) 2020 Prince Kubi Appiah et al. This is an open access article distributed under the Creative Commons Attribution License, which permits unrestricted use, distribution, and reproduction in any medium, provided the original work is properly cited.

\begin{abstract}
Background. Iodine deficiency is a global public health concern as it leads to inadequate production of thyroid hormone in the body, causing too many destructive consequences on the roles and functions of different human organs and muscles including brain growth and can manifest into many damaging effects such as intestinal cerebral impedance, cancer of intestine, breast disorders, and physical deformities like goitre and cretinism to one's body. Despite all these negative effects, there are several important public health programs including universal salt iodization (USI) to improve on households' iodine intake, notwithstanding this, countless families are still eating foods containing less iodine or no iodine at all. Hence, this study examined the intake of iodized salt after years of universal salt iodization and the knowledge on iodized salt among households in the Sissala East Municipality. Method. A descriptive cross-sectional study was adopted to collect data for the study. Data were collected from women in charge of household meal preparation using a semistructured questionnaire and rapid field iodine test kits. The Statistical Package for Social Sciences (SPSS) version 20 was used for the data analysis and presented in tables and graphs. $p$ value $<0.05$ was considered as statistically significant. Findings. Only $41.4 \%$ of the households have good knowledge on benefits of iodized salt and dangers associated with iodine deficiency. It was realized that the health workers (46.6\%) and television were the main sources of information on iodized salt. Household salt usage with adequate $(>15 \mathrm{ppm})$ levels of iodine was $44.0 \%$; however $85.9 \%$ of the salts were stored in covered containers. The study showed significant associations between knowledge on iodized salt and educational level $(p \leq 0.001)$, occupation $(p=0.043)$, religion $(p=0.027)$, and ethnic lineage $(p=0.046)$. Also, the use of iodized salt showed associations with the educational level $(p \leq 0.001)$, occupation $(p=0.003)$, religion $(p=0.042)$, and knowledge on iodized salt $(p \leq 0.001)$. Conclusions. Only about 4 in 10 households were consuming salt with adequate iodine, and this coverage is very low compared with the $90 \%$ or more coverage recommended by WHO/UNICEF/ICCIDD. Having secondary and tertiary education and having good knowledge of iodized salt has a great influence on the use of iodized salt; however, with this low level of knowledge of importance of iodized salt among women responsible for house food preparations, there is the need for health professionals to intensify education and promotion on iodized salt in the area and to monitor and verify iodine content of salts produced and sold in the market all times, as the source of the salt might have contributed to the low levels of iodine in the household salt.
\end{abstract}

\section{Introduction}

Iodine is one of the essential micronutrients found in soil and water, and it is often consumed in several chemical forms [1] and is needed in a diet to support various physiological functions with primary sources being plants grown in iodine-sufficient soil and in seafood, particularly kelp and saltwater fish [2]. Iodine deficiency has adverse effects on all 
ages, but women in reproduction and children are often the most affected groups, and in reproduction, iodine deficiency is linked to adverse pregnancy outcomes such as abortion and miscarriage, brain damage and congenital abnormalities, and perinatal deaths [3].

The severity of the effects of iodine deficiency has been the main stimulus behind global initiatives to eliminate the deficiency through the universal salt iodization (USI) strategy aims to make sure all edible salts are iodized because salt is the most appropriate means for introducing iodine into people's diet as it is consumed by almost every individual [4] and has been proven to be the appropriate approach to eliminate the deficiency. Although USI has been recognized and accepted as very easy to work with and also has been harmless and more inexpensive approach to ensure adequate intake of iodine by all people, still about 266 million school-aged children across some 130 countries including Ghana are having insufficient iodine intake and each year about 38 million newly born children in the developing countries remain unprotected from the lifelong penalties of brain impairment linked with IDD [5].

Though Ghana has legislative laws including food and drugs Act, 1992, under the Provisional National Defence Council Law (PNDCL) 3058, and the Public Health Act, 851, to promote manufacture, packaging, transportation, storage, and sale of iodized salt in the country, the available data suggest that $36.6 \%$ of women with at least a child live in households with no iodized salt and that women living in urban areas are more likely to be in households that use iodized salt (71\%) than women living in rural areas (58\%) [3], and a urine iodine study conducted among Ghanaian children between the ages of 2 to 10 years shows a high prevalence of low urinary iodine, 93.8\% $(<100 \mu \mathrm{g} / \mathrm{dl})$ [6]. Hence, this study examined the intake of iodized salt after years of universal salt iodization and the knowledge on iodized salt among households in the Sissala East Municipality.

\section{Materials and Methods}

2.1. Study Site. The study area has a total landmark of $4,744 \mathrm{~km}^{2}$, forming about $26 \%$ of the total landmass of the whole region, 62 communities, and a population of about 68,578 people with a growth rate of 1.7 per annum. Sissala is the largest ethnic grouping in the study area with some other minority ethnic groups including Kassena and Dagaaba living in the area. About $68 \%$ of the people in the area are into subsistent farming with livestock and poultry reared on small scales. Despite the rearing of the livestock and poultry in the area, the people do not consume much meat but somewhat convey these animals to other parts of Ghana to trade them for cash, which empowers them to buy other life sustainable needs. Because of the area's location in Ghana, the inhabitants do not have easy access to sea foods rich in iodine [7]. The study area has fifty-nine health facilities comprising two hospitals, eight health centres, five clinics, and forty-four Community-based Health Planning and Services (CHPS) compounds which are providing healthcare services to people living within and outside the area. The area also has three tertiary schools comprising a Midwifery Training School, a Teacher Training School, and a Vocational Training School. Also, there are two senior high secondary schools, forty-eight junior high secondary schools, fifty-nine primary schools, and sixty-seven nursery providing formal education to people in the area [8].

2.2. Study Population. Women between the ages of 18 and 60 years, were responsible for household food preparations, and have lived in the study area for more than three months were involved in the study; however, only those who were eager to be part of the study and endorsed the inform consent forms were allowed to participate in the study. On the other hand, people from other countries, severely ill persons, health professionals, and those who have not lived in the study area for up to three or more months were excluded from the study.

2.3. Study Design. A descriptive cross-sectional study used qualitative and quantitative procedures of data gathering to collect data in the study area to determine iodine levels in salt and knowledge level of the people responsible for house food preparations in iodized salt and the factors influencing its use in the municipality.

2.4. Sample Size. Four-hundred and eleven participants were involved, and the sample size was determined using a crosssectional population-based study formula formulated by Cochran: $n=z 2 \times p(q) \div d 2$ [9], where $n$ is the sample size to be determined, $z$ is the reliability coefficient of 1.96 at confidence level of $95 \%, p$ is the prevalence of the household iodized salt of $20 \%(0.2)$ in the population [10], $q$ is $1-p$, and $d 5 \%(0.005)$ is the degree of precision foreseen. With the doubt around the accurate occurrence of iodized salt intake owing to a cluster design, a design effect of 1.5 was measured in the sample size determination. Hence, the sample size turns out to be $n \times 1.5(246 \times 1.5=369)$, and considering a $10 \%$ of nonresponse rate of 369 , the sample size finally came to be 411 participants to ensure that the estimated prevalence fell within $\pm 5 \%$ of the true population coverage with a probability of $95 \%$.

2.5. Sampling Method. A multistage sampling technique was used to select the study participants for the study. Initially, the study area was divided into seven clusters. For each stratum, the list of all communities was obtained and unique numbers were assigned to them, after which two communities were randomly selected. Then, based on the population for each selected community, proportionate distribution was done to the assigned sample size. Also, when the selected communities were entered, the centre of the community was located using a community mapping system. After identification of the centre of the community, north, south, east, and west were written on four pieces of paper and balloting was done to select a direction to start data collection in the community; after the direction has been selected, the data collectors moved in that direction and 
entered the first house facing the selected direction, and after the first house, every order two houses were entered to collect data until the allocated sample size for each community was obtained. In houses where there was more than one household, balloting of yes and no was performed to select one household. Also, in households where there was more than one qualified woman, again balloting of yes and no was performed to select one for data collection, and a sample of household salt was requested for the iodine test.

2.6. Data Collection. The UNICEF supplied Rapid Field Iodine Test Kits manufactured by MBI KITS INTERNATIONAL to Ghana Health Service, and semistructured questionnaires were the tools and methods used to collect data on iodine concentrations of household salts, knowledge on iodized salt, and information about general characteristics of the study participants. The study used a one-on-one interview technique and collection of a small sample of salt for iodine to collect study data. A small sample of household salt was obtained from each respondent and Rapid Field Iodine Test Kits was used to test the Iodine content of the salt following the testing procedure provided by the test kit manufacturer as adding two drops of the test solution to each sample. After adding the solution to the salt, the salt was expected to produce light or deep violet colour within a minute depending on the iodine content of the salt. The colour of the salt was then compared with the colour chart provided by the manufacturer to determine the iodine content. Also, it supplied a test solution which was a recheck solution designed for rechecking and verification of iodine indications at zero and less than $15 \mathrm{ppm}$. The recheck solution is able to lower the $\mathrm{pH}$ in salts with high alkalinity and thus increased the likelihood of detecting slight changes in iodine. So, when no colour appears after a minute, a fresh sample was collected and 5 drops of the recheck solution and 2 drops of test solution were added to the salt as in the user instruction. If no colour appears after the second procedure, then it was concluded and assumed that the salt does not contain iodine. Also, two iodine tests were performed separately and independently by two individuals on household salt due to variations in individual's eyesight; this was to ensure that fair and correct results are obtained. The quality control test of the Rapid Field Iodine Test Kits used was performed by the Ghana Food and Drugs Authority and was approved for the Ghana Health Service to use for routine services. Participants' ages were assessed using their baptismal certificates, birth certificates, antenatal records cards, health insurance cards, and marriage certificates, and participants who did not possess any of these, events calendars were used to determine their ages. Also, knowledge of iodine was determined through a list of responses regarding the benefits of iodized salt and the effects of deficiencies of iodine.

2.7. Ethical Issues. Participant involvement in the study was intentional, and their assent and consent were sought before they were allowed to participate in the study, and before collecting data from the selected communities, approval was sought from the chiefs and elders from all the communities and the Municipal Health Directorate in the study area. And finally, the required ethical procedures concerning the use of human beings in scientific studies were followed and were reviewed and ratified by the Ethical Review Committee of the University of Health and Allied Sciences in Ghana with protocol proof of identity number UHAS-REC A.6[68]1819.

2.8. Data Analysis. The Statistical Package for Social Sciences (SPSS) version 20 software was used to analyze data, and standard deviation, mean, frequencies, and proportions to define the population were presented in charts and tables. Relations between the dependent and independent variables were analyzed using the chi-squared test and logistic regression analytical tools. Statistically, a $p$ value of less than 0.05 was reflected as significant. Households' knowledge of iodine and iodized salt was judged in 11 areas with 11 points score with those who correctly scored between 0 and 5 points categorized as having poor knowledge while those who correctly scored between 6 and 11 points were measured as having good knowledge of iodized salt.

\section{Results}

3.1. General Characteristics of Participants. A total of 411 women who were responsible for their household meal preparations were interviewed with almost half (198 $(48.2 \%))$ of them being within the ages of 18 to 27 years and a mean age of 33.5 years \pm 3.9 standard deviation. As high as $178(43.3 \%)$ of the women have no formal education while only $60(14.6 \%)$ have tertiary education. More than half (231 $(56.2 \%))$ of them were farmers and only $54(13.1 \%)$ were involved in a formal job. Majority (344 (83.7\%)) of them were married out of which $96(27.9 \%)$ were involved in a polygamous marriage. Islamic religion $(365(88.8 \%))$ was the main form of religious expression in the study area, and as high as $354(86.1 \%)$ of the women were from the Sissala tribal lineage, while only $28(6.8 \%)$ were from Kassena lineage (Table 1).

\subsection{Knowledge on Iodized Salt and Source of Information on} Iodized Salt. As high as $220(53.5 \%)$ and 235 (57.2\%) of the women in charge of food preparation in the households do not have enough knowledge on the benefits of iodized salt use and effects of iodine deficiency. Generally, only 170 (41.4\%) on the women had good knowledge of iodized salt (Figure 1). The principal source of information on iodized salt among household members was from health workers 191 (46.6\%) (Figure 2).

\subsection{Iodine Content of Households' Salt and Salt Storage} Practice. Only about 181 (44\%) of the household salts in the study area have adequate iodine levels of greater than $15 \mathrm{ppm}$ (Figure 3). Majority (353 (85.9\%)) of the women stores their salts in covered containers while the rest 47 (14.1\%) stores theirs in open containers (Figure 4). 
TAвle 1: General characteristics of participants.

\begin{tabular}{llcc}
\hline Attribute & & Frequency & Percentage \\
\hline \multirow{3}{*}{ Age (years) } & $18-27$ & 198 & 48.2 \\
& $28-37$ & 129 & 31.4 \\
& $38-47$ & 48 & 11.7 \\
& $48-57$ & 36 & 8.7 \\
\hline \multirow{4}{*}{ Educational level } & None & 178 & 43.3 \\
& Basic & 117 & 28.5 \\
& Secondary & 56 & 13.6 \\
& Tertiary & 60 & 14.6 \\
\hline \multirow{3}{*}{ Occupation } & None & 71 & 17.3 \\
& Petty trade & 55 & 13.4 \\
& Farming & 231 & 56.2 \\
Marital status & Formal job & 54 & 13.1 \\
\hline Type of marriage & Single & 67 & 15.4 \\
$(n=344)$ & Married & 344 & 83.7 \\
\hline \multirow{2}{*}{ Religion } & Monogamous & 248 & 72.1 \\
& Polygamous & 96 & 27.9 \\
\hline \multirow{2}{*}{ Ethnicity } & Christianity & 46 & 11.2 \\
& Islam & 365 & 88.8 \\
\hline & Sissala & 354 & 86.1 \\
& Dagaaba & 29 & 7.1 \\
& Kassena & 28 & 6.8 \\
\hline
\end{tabular}

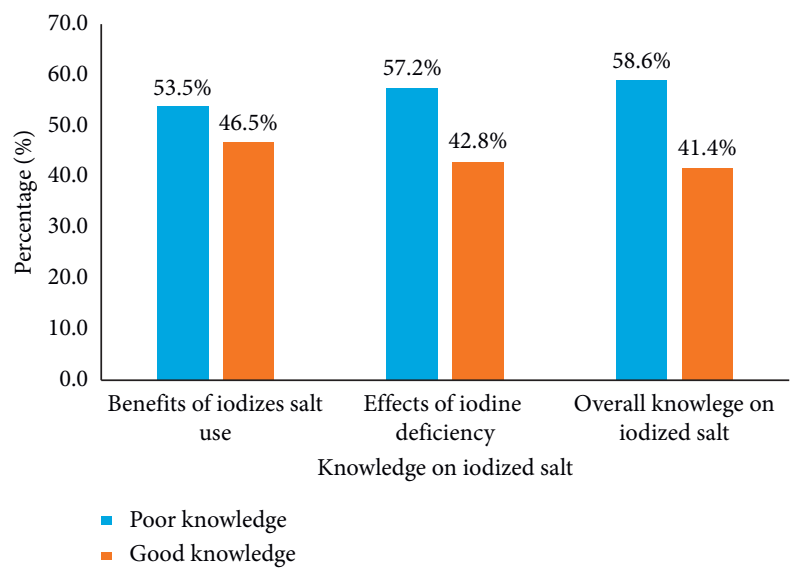

FIgURE 1: Knowledge on iodized salt.

3.4. Factors Influencing Households' Knowledge on Iodized Salt. The study revealed significant associations between household knowledge on iodized salt and educational level $(p \leq 0.001)$, occupation $(p=0.043)$, religion $(p=0.027)$, and ethnicity ( $p=0.046)$. To further scrutinize the power of the associations, multiple logistic analysis was performed to check associations between household good knowledge on iodized salt and the descriptive variables, and this confirmed the associations between good knowledge on iodized salt and basic education (OR (2.47); CI (1.48-4.10), $p=0.001)$, secondary education (OR (5.29) CI $(2.78-10.01) p \leq 0.001)$, and tertiary education (OR (23.9); CI (10.48-33.75); $p \leq 0.001$ ). The multiple logistic regressions also showed associations between good knowledge on iodized salt and formal job (OR (5.66); CI (2.51-12.10); $p=0.002)$ and Islamic religion (OR (0.50); CI (0.27-0.93); $p=0.029)$. The

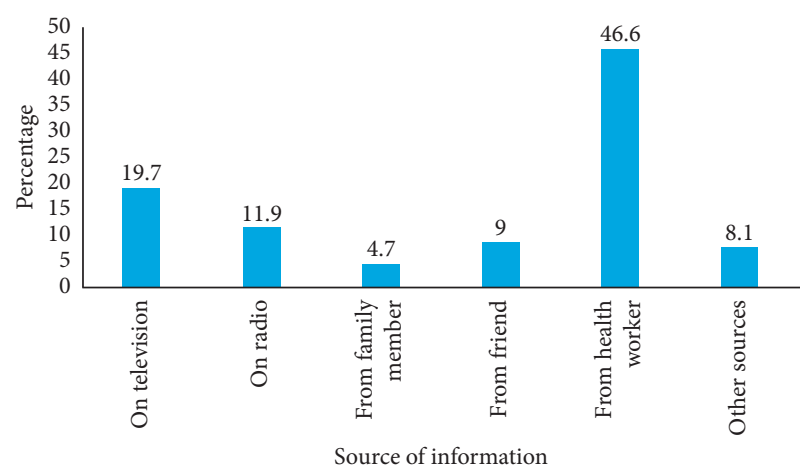

Figure 2: Source of information on iodized salt.

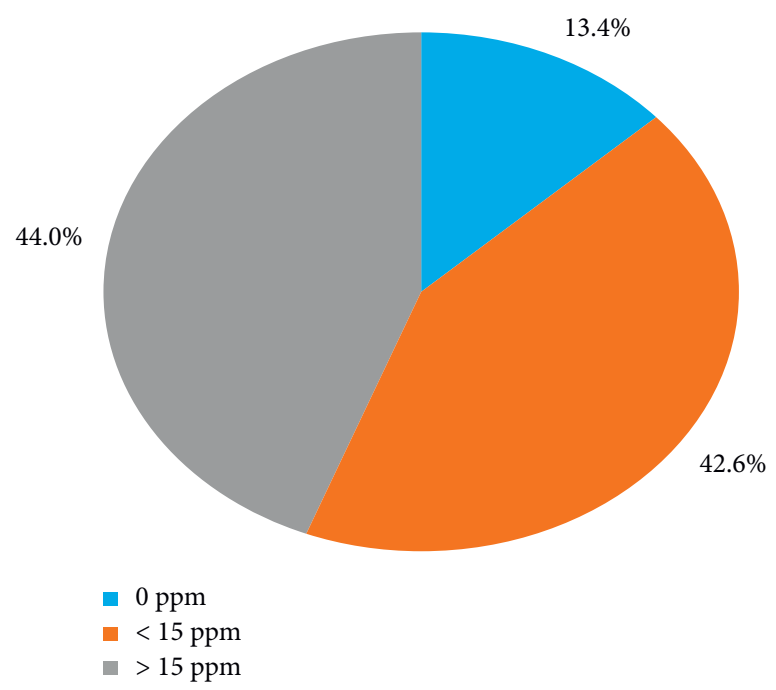

Figure 3: Iodine content of households' salt.

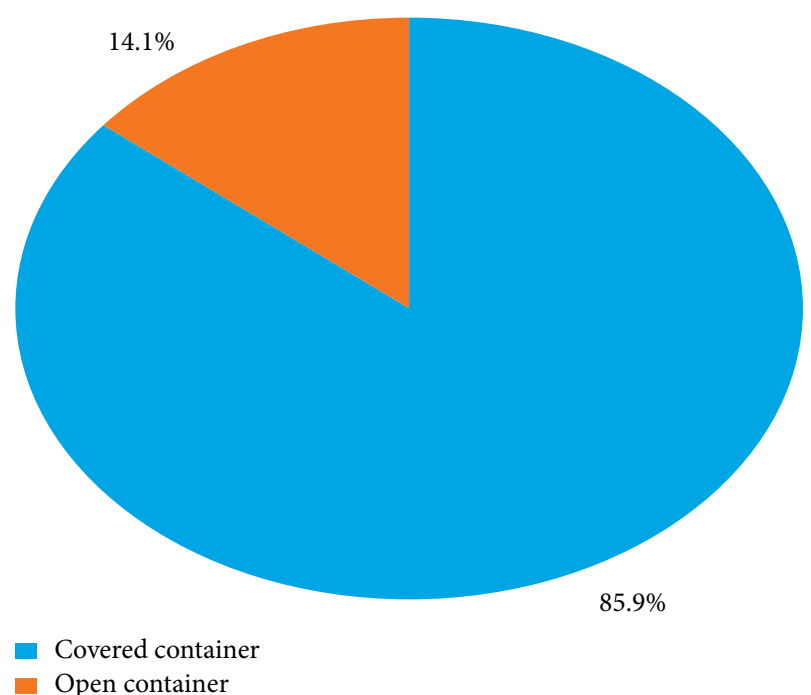

FIgURE 4: Household salt storage practice.

associations showed that those with basic, secondary, and tertiary education were about $2.5,5.3$, and 24 times more likely to have good knowledge on iodized salt than those who 
have never been to school, while those having formal jobs were about 5.7 times more likely to have good knowledge than those who were unemployed. Also, those involved in Islamic religion were 50\% less likely to have good knowledge of iodized salt than Christians. In addition, when variables that were having associations with good knowledge on iodized salt from bivariate analysis were alone tested for strength of associations, the following was further confirmed: for those with basic education (AOR (2.46); CI (1.43-14.22); $p=0.001$ ), secondary education (AOR (5.31); CI (3.60-30.83); $p \leq 0.001$ ), and tertiary education (AOR (56.97); CI (11.34-51.59); $p \leq 0.001)$. This also indicated that having basic, secondary, and tertiary education was about $2.5,5.3$, and 57 times, respectively, was more likely to have good knowledge of iodized salt than those with no education (Table 2).

3.5. Factors Associated with Iodized Salt Usage in the Households. The study revealed significant associations between the use of iodized salt (adequate iodine) and educational level $(p \leq 0.001)$, occupation $(p=0.003)$, religion $(p=0.042)$, ethnicity $(p=0.002)$, and knowledge on iodized salt $(p \leq 0.001)$. To further explore the strength of associations, multiple logistic analysis was done to confirm associations between the use of iodized salt and the explanatory variables, and this confirmed the associations between use of iodized salt and secondary education (OR (2.97) $\mathrm{CI}(1.60-5.51) p=0.002)$ and tertiary education (OR (6.21); CI $(3.20-12.05) ; p=0.001)$. The multiple logistic regressions also showed associations between use of iodized salt and farming (OR (2.29); CI $(0.17-0.81) ; p=0.002)$, Islamic religion (OR (0.50); CI $(0.27-0.93) ; p=0.029)$, Kassena ethnic lineage (OR (0.39); CI (0.03-0.31); $p=0.004)$, and good knowledge on iodized salt (OR (2.70); CI $(1.80-14.05) ; p=0.002)$. The associations showed that those with secondary and tertiary education were about 3 and 6.2 times more likely to use iodized salt than those who have never been to school, while those into farming were about 2.3 times more likely to use salt with adequate iodine than those who were unemployed. Also, those belonging to the Islamic religion were about $54 \%$ less likely to use iodized salt than Christians. Moreover, those from Kassena ethnic lineage were $61 \%$ less likely to use iodized salt than those from Sissala ethnic lineage, and those with good knowledge on iodized salt were 2.7 times more likely to use iodized salt than those with poor knowledge. Furthermore, when variables that were having associations with use of iodized salt from bivariate analysis were alone tested for power of associations, the following was further confirmed: those with secondary education (AOR (2.34); CI (1.16-4.72); $p \leq 0.017)$, tertiary education (AOR (5.80); CI (1.57-21.41); $p \leq 0.008)$, farming (AOR (2.43); CI (0.22-0.83); $p=0.012)$, Kassena ethnic lineage (AOR (0.40); CI (0.04-0.52); $p=0.013$ ), and good knowledge on iodized salt (AOR (3.20); CI (2.34-36.01); $p=0.001)$. This also indicated that having secondary and tertiary education was about 2.3 and 5.8 times, respectively, more likely to have good knowledge on iodized salt than those with no education, also those into farming were 2.4 times than those with no job, Kassena ethnic lineage were $60 \%$ less likely than Sissala ethnic lineage, and those with good knowledge on iodized salt were 3.2 times more likely to use iodized salt than those with poor knowledge (Table 3).

\section{Discussion}

Universal salt iodization has been one of the most effective public health interventions adopted by the WHO/UNICEF/ ICCIDD for the global eradication of iodine deficiency disorders (IDDs). At the moment, merely $41.4 \%$ of the women in control of household diet preparations in Sissala East have worthy knowledge on iodized salt, perversely to a parallel investigation carried out in Hohoe area in the Volta Region (59.3\%) [11] and Gushegu District in the northern region of Ghana (53.5\%) [10]. However, these revelations from the Hohoe, Gushegu, and current studies were far below the findings (79.9\%) of the current Ghana's Demographic and Health Survey [3]. It would be an interesting study to ascertain what might have contributed to the knowledge disparities within the various areas of the country, even though the educational level of the people and the content of public education and the extent of the education including its coverage on iodized salt may be different and a major factor.

On attitude towards storage of salt in the households, the high percentage $(85.9 \%)$ of good storage practices (stored salt in covered container) observed is in uniform with findings (92.3\%) of a similar study carried out in the Laelay Maychew District in Ethiopia [12]. This practice is very important in the promotion of iodine consumption and must be highlighted and encouraged in any public education as iodized salt depreciates its iodine contents when not stored in proper conditions like closed plastic bags, sealed waterproof materials, or closed containers [13]. In contrary, the findings are in contrast with a similar study conducted in the Hohoe Municipality of Ghana (69.8\%) [11].

Iodine content of salts in households in the current study area was not encouraging as $44.0 \%$ of salts contained the recommended levels of iodine above $15 \mathrm{ppm}$, notwithstanding this, the findings have some appreciation over the $20 \%$ in Gushegu district in the Northern Region, the 24.2\% in Hohoe municipality in the Volta Region, and $34.5 \%$ in the Multiple Indicator Cluster Survey in Ghana [10, 11, 14]. Though the iodine content of salts in the study area is much appreciated over other areas in Ghana, it is still far below the WHO's coverage target of more than $90 \%$. These disparities could also be due to the iodine content of salts produced and sold in the markets and calls for the policies on salt production and marketing to be revisited and enforced properly.

There was a relationship between good knowledge of iodized salt and level of education $(p \leq 0.001)$, occupation $(p=0.043)$, religion $(p=0.027)$, and ethnicity $(p=0.046)$, and it indicated that households with tertiary education are 24 times more likely to have good knowledge on iodized salt than those with no education, and those with formal jobs are also 6 times more likely to have good knowledge than those 
TABLE 2: Factors influencing households' knowledge on iodized salt.

\begin{tabular}{|c|c|c|c|c|c|c|}
\hline \multirow[b]{2}{*}{ Attribute } & \multicolumn{2}{|c|}{ Knowledge level } & \multicolumn{2}{|c|}{ Pearson $\mathrm{Chi}^{2}$} & \multirow[b]{2}{*}{ OR (95\% CI); $p$ value } & \multirow[b]{2}{*}{$\operatorname{AOR}(95 \% \mathrm{CI}) ; p$ value } \\
\hline & $\begin{array}{c}\text { Poor } \\
n=241(\%)\end{array}$ & $\begin{array}{c}\text { Good } \\
n=170(\%)\end{array}$ & $\mathrm{Chi}^{2}$ & $p$ value & & \\
\hline \multicolumn{7}{|l|}{ Age (years) } \\
\hline $18-27$ & $107(44.4)$ & $91(53.5)$ & \multirow{4}{*}{8.723} & \multirow{4}{*}{0.143} & - & \\
\hline $28-37$ & $74(30.7)$ & $55(32.4)$ & & & $0.90(0.58-2.40) 0.651$ & \\
\hline $38-47$ & $35(14.5)$ & $13(7.6)$ & & & $0.44(0.22-1.87) 0.204$ & \\
\hline $48-57$ & $25(10.4)$ & $11(6.5)$ & & & $0.45(0.21-1.90) 0.462$ & \\
\hline \multicolumn{7}{|c|}{ Educational level } \\
\hline None & $134(55.6)$ & $44(25.9)$ & \multirow{4}{*}{87.365} & \multirow{4}{*}{$\leq 0.001$} & - & - \\
\hline Basic & $70(29.1)$ & $47(27.6)$ & & & $2.47(1.48-4.10) \mathbf{0 . 0 0 1}$ & $2.46(1.43-14.22) 0.001$ \\
\hline Secondary & $23(9.5)$ & $33(19.4)$ & & & $5.29(2.78-10.01) \leq \mathbf{0 . 0 0 1}$ & $5.31(3.60-30.83) \leq \mathbf{0 . 0 0 1}$ \\
\hline Tertiary & $14(5.8)$ & $46(27.1)$ & & & $23.9(10.48-33.75) \leq \mathbf{0 . 0 0 1}$ & $56.97(11.34-51.59) \leq \mathbf{0 . 0 0 1}$ \\
\hline \multicolumn{7}{|l|}{ Occupation } \\
\hline None & $42(17.4)$ & $29(17.1)$ & \multirow{4}{*}{49.008} & \multirow{5}{*}{0.043} & - & - \\
\hline Petty trade & $28(11.6)$ & $27(15.9)$ & & & $1.38(0.63-3.01) 0.426$ & $1.91(0.75-4.81) 0.172$ \\
\hline Farming & $150(62.3)$ & $81(47.6)$ & & & $0.62(0.36-1.07) 0.086$ & $1.02(0.49-2.12) 0.963$ \\
\hline Formal job & $21(8.7)$ & $33(19.4)$ & & & $5.66(2.51-12.10) 0.002$ & $0.41(0.08-2.24) 0.306$ \\
\hline \multicolumn{6}{|c|}{ Marital status } & \\
\hline Single & $35(14.5)$ & $32(18.8)$ & \multirow{3}{*}{6.669} & \multirow{3}{*}{0.083} & - & \\
\hline Married & $206(85.5)$ & $138(81.2)$ & & & $0.67(0.37-1.20) 0.199$ & \\
\hline \multicolumn{5}{|l|}{ Religion } & & \\
\hline Christianity & $20(8.3)$ & $26(15.3)$ & \multirow{3}{*}{4.908} & \multirow{3}{*}{0.027} & - & - \\
\hline Islam & $221(91.7)$ & $144(84.7)$ & & & $0.50(0.27-0.93) \mathbf{0 . 0 2 9}$ & $1.47(0.58-3.70) 0.415$ \\
\hline \multicolumn{5}{|l|}{ Ethnicity } & & \\
\hline Sissala & $214(88.8)$ & $140(82.4)$ & \multirow{3}{*}{14.367} & \multirow{3}{*}{0.046} & - & - \\
\hline Dagaaba & $13(5.4)$ & $16(9.4)$ & & & $1.17(0.29-4.5) 0.825$ & $1.19(0.22-6.43) 0.837$ \\
\hline Kassena & $14(5.8)$ & $14(8.2)$ & & & $0.50(0.10-2.40) 0.390$ & $0.77(0.12-4.79) 0.781$ \\
\hline
\end{tabular}

TABLE 3: Factors associated with iodized salt usage in the households.

\begin{tabular}{|c|c|c|c|c|c|c|}
\hline \multirow[b]{2}{*}{ Attribute } & \multicolumn{2}{|c|}{ Iodine content in salt } & \multicolumn{2}{|c|}{ Pearson $\mathrm{Chi}^{2}$} & \multirow[b]{2}{*}{ OR $(95 \%$ CI $) p$ value } & \multirow[b]{2}{*}{ AOR $(95 \%$ CI $) p$ value } \\
\hline & $\begin{array}{l}\text { Inadequate } \\
n=230(\%)\end{array}$ & $\begin{array}{c}\text { Adequate } \\
n=181(\%)\end{array}$ & $\mathrm{Chi}^{2}$ & $p$ value & & \\
\hline \multicolumn{7}{|l|}{ Age (years) } \\
\hline $18-27$ & $109(47.4)$ & $89(49.2)$ & \multirow{4}{*}{4.014} & \multirow{4}{*}{0.675} & - & \\
\hline $28-37$ & $72(31.3)$ & $57(31.5)$ & & & $0.91(0.58-1.40) 0.686$ & \\
\hline $38-47$ & $27(11.7)$ & $21(11.6)$ & & & $0.90(0.74-1.60) 0.735$ & \\
\hline $48-57$ & $22(9.6)$ & $14(7.7)$ & & & $0.51(0.24-1.01) 0.081$ & \\
\hline \multicolumn{7}{|c|}{ Educational level } \\
\hline None & $116(50.4)$ & $62(34.3)$ & \multirow{4}{*}{41.676} & \multirow{4}{*}{$\leq 0.001$} & & \\
\hline Basic & $72(31.3)$ & $45(24.9)$ & & & $1.29(0.79-2.10) 0.301$ & $1.31(0.77-2.23) 0.326$ \\
\hline Secondary & $23(10.0)$ & $33(18.2)$ & & & $2.97(1.60-5.51) \mathbf{0 . 0 0 2}$ & $2.34(1.16-4.72) 0.017$ \\
\hline Tertiary & $19(8.3)$ & $41(22.6)$ & & & $6.21(3.20-12.05) 0.001$ & $5.80(1.57-21.41) \mathbf{0 . 0 0 8}$ \\
\hline \multicolumn{7}{|l|}{ Occupation } \\
\hline None & $29(12.6)$ & $42(23.2)$ & \multirow{4}{*}{48.525} & \multirow{4}{*}{0.003} & & \\
\hline Petty trade & $21(9.1)$ & $34(18.8)$ & & & $1.23(0.55-2.76) 0.611$ & $2.68(0.70-4.07) 0.248$ \\
\hline Farming & $162(70.5)$ & $69(38.1)$ & & & $2.29(0.17-0.81) \mathbf{0 . 0 0 2}$ & $2.43(0.22-0.83) \mathbf{0 . 0 1 2}$ \\
\hline Formal job & $18(7.8)$ & $36(19.9)$ & & & $1.64(0.77-3.48) 0.197$ & $2.52(0.14-1.99) 0.343$ \\
\hline \multicolumn{7}{|c|}{ Marital status } \\
\hline Single & $28(12.2)$ & $39(21.5)$ & \multirow{3}{*}{7.194} & \multirow{3}{*}{0.117} & - & \\
\hline Married & $202(87.8)$ & $142(78.5)$ & & & $0.46(0.25-1.84) 0.128$ & \\
\hline \multicolumn{5}{|l|}{ Religion } & & \\
\hline Christianity & $18(7.8)$ & $28(15.5)$ & \multirow{2}{*}{16.363} & \multirow{2}{*}{0.042} & - & - \\
\hline Islam & $212(92.2)$ & $153(84.5)$ & & & $0.46(0.24-0.86) \mathbf{0 . 0 1 6}$ & $0.84(0.36-1.98) 0.698$ \\
\hline \multicolumn{7}{|l|}{ Ethnicity } \\
\hline Sissala & $206(89.6)$ & $148(81.8)$ & \multirow{3}{*}{24.981} & \multirow{3}{*}{0.002} & & \\
\hline Dagaaba & $13(5.6)$ & $16(8.8)$ & & & $0.53(0.13-2.24) 0.389$ & $0.53(0.11-2.51) 0.426$ \\
\hline Kassena & $11(4.8)$ & $17(9.4)$ & & & $0.39(0.03-0.31) \mathbf{0 . 0 0 4}$ & $0.40(0.04-0.52) \mathbf{0 . 0 1 3}$ \\
\hline \multicolumn{7}{|c|}{ Knowledge level } \\
\hline Poor & $159(69.1)$ & $82(45.3)$ & \multirow{2}{*}{27.23} & \multirow{2}{*}{$\leq 0.001$} & - & - \\
\hline Good & $71(30.9)$ & $99(54.7)$ & & & $2.70(1.80-14.05) \mathbf{0 . 0 0 2}$ & $3.20(2.34-36.01) \mathbf{0 . 0 0 1}$ \\
\hline
\end{tabular}


without jobs. This means as individual's educational level changes from lower to higher level, his/her knowledge about iodized salt increases and is in agreement with the Hawassa Town in Southern Ethiopia, the Tehranian women in Turkey, and the Australian pregnant women studies [15-17].

The present study also noticed that once a person has good knowledge of iodized salt, the likelihood of that person using iodized was very high and that knowledge on iodized salt $(p \leq 0.001)$ and individuals' educational level $(p \leq 0.001)$ was associated with iodized salt use. It further confirmed that good knowledge about iodized salt and tertiary education was 2.7 and 6.2 times more likely to consume iodized salt. These findings were similar to that of the Laelay Maychew District in the Northern Ethiopia study which revealed that the knowledge level of respondents about iodized salt had influence on its usage as $51.6 \%$ of those who had good knowledge were using iodized salt compared with the lower proportions of $22.6 \%$ among those who had poor knowledge, and also $54.5 \%$ of respondents who had access to formal education were using iodized salt compared with $19.6 \%$ among those who did not have access to formal education [12].

\section{Conclusion}

Only about 4 in 10 households were consuming salt with adequate iodine, and this coverage is very low compared to the $90 \%$ or more coverage recommended by WHO/UNICEF/ICCIDD. Having secondary and tertiary education and having good knowledge of iodized salt have a great influence on the use of iodized salt; however, with this low level of knowledge of importance of iodized salt among women responsible for house food preparations, there is the need for health professionals to intensify education and promotion on iodized salt in the area and to monitor and verifying the iodine content of salts produced and sold in the market all times, as the source of the salt might have contributed to the low levels of iodine in the household salt.

\subsection{Recommendations}

(1) The study area's Iodized Salt Committee with the help of the regulatory bodies should try to conduct regular iodine tests on salts in markets in the area to ascertain the iodine content of salts being sold to the households

(2) Health staff should be empowered with the necessary logistics and knowledge needed, with well-motivated packages to enable them to intensify public education and campaigns on iodized salt in the study area to increase iodized salt consumption and good storage practices

(3) Children are known to be the agents of change; therefore, the Ghana Education Service in collaboration with Ghana Health Service should work together to intensify school health education activities to increase the awareness among children on the benefits and dangers of iodine deficiency.
(4) Regulatory bodies such as Ghana Standard Authority, the Food and Drugs Authority, and Security agencies should intensify their monitoring activities to ensure that all salt produced in the country is fortified with required levels of iodine and standards

(5) We also recommend that further studies on urine iodine should be conducted to ascertain whether those identified to consume iodized salt are meeting their body requirements.

\section{Data Availability}

The study followed the required ethical procedures regarding the use of human subjects for scientific studies; therefore, all materials could be made available after written approval from the Ethical Review Committee of the University of Health and Allied Sciences in Ghana, the body that reviewed and approved for the study.

\section{Additional Points}

Study Limitations. Individual's eyesight variations to detect a colour change on tested salt and difficulty in decisionmaking on the borderline situation of $<15$ and $>15 \mathrm{ppm}$. However, the trained nutritionist made efforts to limit errors as a result of these challenges.

\section{Conflicts of Interest}

The authors declare that that they have no conflicts of interest regarding the publication of this paper.

\section{Acknowledgments}

The authors declare that that they have no conflicts of interest regarding the publication of this paper.

\section{References}

[1] M. B. Zimmermann, "Iodine deficiency," Endocrine Reviews, vol. 30, no. 4, pp. 376-408, 2009.

[2] C. D. Meletis, "Iodine," Journal of Evidence-Based Complementary \& Alternative Medicine, vol. 16, no. 3, pp. 190-194, 2011.

[3] Ghana Statistical Service (GSS), Ghana Health Service (GHS), and ICF International, Ghana Demographic and Health Survey 2014, GSS, GHS, and ICF International, Rockville, MD, USA, 2015.

[4] B. De Benoist, M. Andersson, I. Egli, B. Takkouche, and H. Allen, Iodine Status Worldwide: WHO Global Database on Iodine Deficiency, World Health Organization, Geneva, Switzerland, 2004.

[5] S. Bali, A. R. Singh, A. Tomar, P. K. Nayak, and R. Belwal, "On the road of universal salt iodization: the prevalence of iodine deficiency disorder among school going children in Damoh district, Madhya Pradesh," AABS, vol. 5, pp. A42-A47, 2018.

[6] G. Egbi, "Prevalence of vitamin a, zinc, iodine deficiency and anaemia among 2-10 year-old Ghanaian children," African Journal of Food, Agriculture, Nutrition and Development, vol. 12, no. 2, pp. 5946-5958, 2012.

[7] Ghana Statistical Service, 2010 Population and Housing Census Report, Ghana Statistical Service, Accra, Ghana, 2014. 
[8] GHS Annual Report, 2018, Ghana Health Service: Sissala East Annual Report.

[9] G. W. Snedecor and W. G. Cochran, Statistical Methods, Iowa State University Press, Ames, IA, USA, 1989.

[10] D. Chirawurah, S. Apanga, and J. Addah, "Assessing iodized salt use in rural Northern Ghana: a mixed method approach," Food and Public Health, vol. 5, no. 3, pp. 70-76, 2015.

[11] A. N. Sarah, K. A. Prince, S. A. Yao, A. A. Geoffrey, K. T. Wisdom, and K. Margaret, "Knowledge on iodized salt use and iodine content of salt among households in the Hohoe municipality, Volta region-Ghana," Central African Journal of Public Health, vol. 2, no. 1, pp. 1-10, 2016.

[12] B. Gidey, K. Alemu, A. Atnafu, M. Kifle, Y. Tefera, and H. R. Sharma, "Availability of adequate iodized salt at household level and associated factors in rural communities in Laelay Maychew District, Northern Ethiopia: a cross sectional study," Journal of Nutrition and Health Sciences, vol. 1, no. 4, p. 1, 2015.

[13] M. L. D. Sebotsa, A. Dannhauser, W. F. Mollentze, G. M. Mollentze, F. A. Mahomed, and P. L. Jooste, "Knowledge, attitudes and practices regarding iodine among patients with hyperthyroidism in the Free State, South Africa," South African Journal of Clinical Nutrition, vol. 22, no. 1, 2009.

[14] Ghana Statistical Service, Multiple Indicator Cluster Survey, 2011: Monitoring the Situation of Children, Women, and Men; with an Enhanced Malaria Module and Biomarker, Ghana Statistical Service, Accra, Ghana, 2011.

[15] M. Girma, E. Loha, A. Bogale, N. Teyikie, C. Abuye, and B. J. Stoecker, "Iodine deficiency in primary school children and knowledge of iodine deficiency and iodized salt among caretakers in Hawassa Town: Southern Ethiopia," Ethiopian Journal of Health Development, vol. 26, no. 1, pp. 30-35, 2012.

[16] P. Mirmiran, P. Nazeri, P. Amiri, L. Mehran, N. Shakeri, and F. Azizi, "Iodine nutrition status and knowledge, attitude, and behavior in Tehranian women following 2 decades without public education," Journal of Nutrition Education and Behavior, vol. 45, no. 5, pp. 412-419, 2013.

[17] K. E. Charlton, L. Gemming, H. Yeatman, and G. Ma, "Suboptimal iodine status of Australian pregnant women reflects poor knowledge and practices related to iodine nutrition," Nutrition, vol. 26, no. 10, pp. 963-968, 2010. 